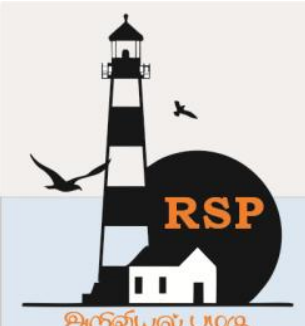

INTERNATIONAL RESEARCH JOURNAL ON ADVANCED SCIENCE HUB

ISSN : $2582-4376$
Open Access

RSP SCIENCE HUB

(The Hub of Research Ideas)

Available online at www.rspsciencehub.com

Special Issue of First International Conference on Advancements in Management, Engineering and Technology (ICAMET 2020)

\title{
Development of Cost Model for Heat Exchanger of Residential and Industry Application
}

Sanjeevakumar Patil ${ }^{1}$, Shivaraj $B W^{2}$, Keshav $V^{3}$

${ }^{1}$ Student, Department of MechanicalEngineering, RV College of Engineering, Bengalure-560059

${ }^{2}$ Assistant Professor,Department of Mechanical Engineering, RV College of Engineering, Bengalure560059

${ }^{3}$ ProductivityManager, Trane Technologies Pvt Ltd,Bengaluru-560029

sanjeevakumarp.pdm18@rvce.edu.in ${ }^{1}$

\begin{abstract}
Manual cost estimation process for heat exchanger having the less accuracy when compared with supplier's quotation and having several challenges like costing is based on the assumption, inaccurate process time estimation, data collection from the plant are not up to date. The objective of this work was to develop an accurate, reliable and time-saving cost model using the aPriori cost estimation tool for heat exchanger. aPriori cost estimation tool consist of two parts are Virtual Production Environment (VPE) and Cost Model (CM). VPE is the digital copy of the specific plant. To develop the VPE required data was material data, machine data, process data and plant data and created the template to collect the data from the plant. CM was written with Cost Scripting Language (CSL) are used to build logic and formulae and defined the cost taxonomy, machine selection rule and material selection rule was developed. VPE and CM was developed for manual brazing, robotic brazing, tube expansion, tube insertion and turret press process. Validated the manufacturing times consist of cycle time 103 seconds and labor time 103 seconds and cost variables consist of labor cost $\$ 0.87$, direct overhead cost $\$ 0.03$, addition direct cost $\$ 0.20$, total variable cost $\$ 1.10$ and fully burdened cost $\$ 1.46$ for manual brazing process and similarly validated the cost parameters for the robotic brazing, tube insertion, tube expansion and turret press process successfully. aPriori cost estimation model reduced the overall production time, improve the productivity and quality of the product. aPriori cost model estimated that manufacturing cost of fin and tube heat exchanger around annual saving $19 \%$ of manual process cost estimation of the fin and tube heat exchanger.
\end{abstract}

Keywords: Cost Model, Heat Exchanger, Residential and Industry Application

\section{Introduction}

Manufacturing Enterprises are currently facing extreme competition due to complex customer requirements/changes and other challenges such as technological, social, environmental, legal and political issues. In order to remain competitive, manufacturing companies must implement strategies and techniques that allow them to be flexible in design, production, and service.
However, it is estimated that around $70 \%$ of the production costs in the design phase are determined with very limited production information [1]. Most cost sensitive decisions are made in the early stages of the design phase. Because it is necessary to help designers understand the cost implications of their design solutions. Cost modeling empowers an organization to make strategic decisions based on 


\section{www.rspsciencehub.com}

accurate information. The advanced cost modeling tools promise high-quality and precision solutions because they take into account material costs, labor costs, service and maintenance costs, production costs, and profit margins for the production of a product or service [2]. Differences in process, use, capacity, geographical location, and other factors related to production or production must be taken into account. With cost modeling, decision makers can make strategic decisions based on data and insights [3]. Product cost management software provides a way to track and control the costs of designing and processing manufactured goods or other intensively developed products. This software was developed to search for drivers for costs and to compare different designs for feasibility and cost efficiency. This is used wherever cost control is paramount. This software can stand alone or is offered as a module in the PLM (Product Lifecycle Management) package and top cost estimation tools are aPriori product cost management, Siemens PLM software, EasyKost software and Price Cost Analytics (PLA) product cost estimation tool [4]. Cost modeling makes it easy for companies to improve supplier relationship management. This allows top managers to identify the right suppliers and strategically deliver materials and goods at optimal prices. It also allows coordination between organizations and suppliers, including in the design phase itself and using supplier market insights. Cost modeling creates long-term relationships and builds trust with buyers and suppliers [5].

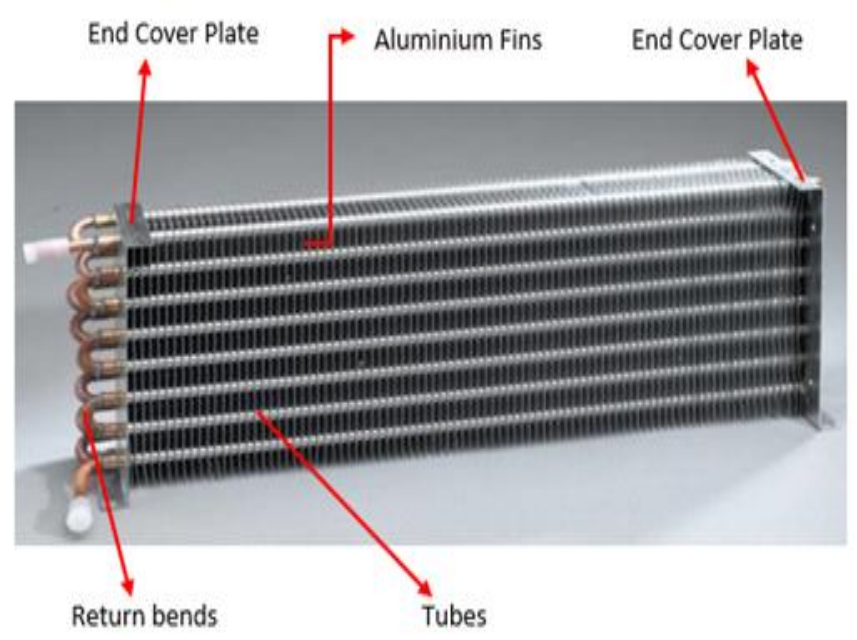

Fig 1 Aluminium fin and tube heat exchanger
Fig 1 shows the aluminium finned tube heat exchangers and parts of the aluminium fin and tube heat exchanges is end cover plate, return bend, tubes and aluminium fins. This type of heat exchanger is used in a variety of domestic applications and as an industrial heat exchanger. Air heat exchangers such as evaporator coils for air conditioning systems are usually fin type heat exchangers [6]. Activity-based costs are the costing method used to transfer plant resources and their consumption activities to company products or services. Unlike job costing method, activitybased costs include more indirect costs in direct production cost to make easier pricing decisions and when applied properly, activity-based costs can help producers get clarity about profitable and unprofitable products [7]. This is useful for determining the product life cycle or identifying areas where improvements can be made. The process can result in better returns for existing products. Proponents of activity-based costs believe that this is a more accurate way to connect overhead costs with income-generating activities, which in turn increases and increases factory cost control activities and more accurate solutions to the product life cycle [8]. aPriori is a product cost management platform that provides initial cost visibility, consistent cost practices for all members of the product team, and higher productivity from cost-effective components. This all leads to a more cost-conscious culture where everyone is considering profitability with each decision they make. aPriori programming and administrations create hard-dollar item cost investment funds for discrete assembling associations [9]. Utilizing aPriori's constant item cost appraisals, representatives in sourcing, assembling and configuration designing settle on increasingly educated choices that drive costs out of items preand after creation. With aPriori, discrete makers dispatch items at cost targets, amplify investment funds in re-work extends, and abstain from overpaying for re-appropriated parts. Accordingly, aPriori clients fundamentally decrease item costs and quantifiably improve generally money related execution, all while conveying high-esteem items to their clients. aPriori cost estimation tool have two major parts has VPE and CM [10]. 


\section{Manual Cost Estimation Process}

Currently in an organization, they are using the spreadsheet approach for cost estimation of heat exchanger. For cost estimation of materials, they are entered the details of the materials like name of the material, quantity, materials dimensions such as thickness, width, length are defined in the cells and also density, price per unit and required variables are created in the cells. Formulas are entered into the cell where you want the value to be located. A formula is created by first entering $=$ (the equals sign) and then adding, subtracting, multiplying, etc. the values of other cells.

\subsection{Material cost calculation}

Manual cost estimation having the spread sheet consist of material name, outer diameter, inner diameter, thickness, width, length, density, price per unite and other required variables are defined in the cells of the spreadsheet. Formulas are entered into the cell where you want the value to be located and required formula are defined in the cells to get the cost of the materials.

Total material price $=$ PRODUCT $(\mathrm{N} 7, \mathrm{M} 7) \ldots . .1$

Where N7 $=$ Total Material weight $(\mathrm{Kg})$ and

\section{M7 = Material Price per weight $(\$ / K g)$}

Equation 1 shows that total material price is product of total material weight and material price per weight.

Total Material Price $=1.648 * 1.9=\$ 3.13$

Total material weight $=$ PRODUCT $(L 7$, C7) $\ldots .2$

Where L7 = Material weight $(\mathrm{Kg})$

$$
\text { C7 = Quantity (Numbers of parts) }
$$

Equation 2 shows that total material weight is product of material weight and Quantity.

Total Material weight $=0.235 * 7=1.648 \mathrm{Kg}$

Material weight $=$ RODUCT $(\mathrm{G} 7, \mathrm{H} 7, \mathrm{I} 7, \mathrm{~K} 7) \ldots . .3$

Where G7 = Thickness of the sheet $(\mathrm{mm})$

$\mathrm{H} 7=$ Width of the sheet $(\mathrm{mm})$

I7 = Height of the sheet $(\mathrm{mm})$

$\mathrm{K} 7$ = Material density $(\mathrm{Kg} / \mathrm{mm} 3)$

Equation 3 shows that material weight is product of thickness, width, height of the sheet and material density.
Material weight $=1.4605 * 101.6 * 609.6 *$ $0.000002601911=0.235 \mathrm{Kg}$

\subsection{Predefined parts manufacturing costs and assumptions on variables cost}

For Fin and tube heat exchanger consist of Fin parts, end cover plate, copper tubes, return bends connecting tubes to distributor and assembly process. In manual costing method for parts cost are based on the previous manufacturing rates and based on some assumption final part cost was calculating. For example fin manufacturing cost of the fin specification of $16 * 0.09 * 21 * 9.13$ (Depth*Thickness*FinPerInch*Height) was \$ $0.825 \mathrm{USD} / \mathrm{KG}$. Overhead rates, selling, general administrative cost, profit and packaging cost details and this cost are calculating based on the assumption from percentage of total cost and percentage of material cost. For example Equipment Overhead Rate is 5\% of material cost, Fixed Overhead Rate is $12 \%$ of material cost, SG\&A Rate is summation of $11 \%$ of total cost and $15 \%$ material cost and profit margin is summation of $13 \%$ of total cost and $7 \%$ material cost and manual estimation considering that some static data like labor rate is $\$ 3.71 / \mathrm{Hr}$, Aluminium cost $\$ 1.90$ $/ \mathrm{Kg}$, Electricity cost $\$ 0.19 / \mathrm{kWh}$ and coper cost $\$$ $6.11 / \mathrm{Kg}$. this variables are predefined in the spreadsheet and used for the part cost calculation but in actual scenario the material rate, electricity rate, labor arte will change with time hence accuracy of this cost estimation method was less.

\section{Project Methodology}

The Fig 2 describes the methodology followed for completing the project work, various tools and instruments which were employed at various stages of the project. Methodology followed to complete the project included preparation of template to collect the plant data, machine data, material data, and process data. Collected the required data from plant and review of the collected data. After the data validated then development of VPE will start and development of initial cost model by using the Cost Scripting language (CSL) to add the cost taxonomy, machine selection, materials selection and process routine selection rule is defined in cost model and validation of cost model will be performed with respect to material selection, machine selection and process routine selection rules are validated and cost the heat exchanger with new developed model and validate the cost details 
www.rspsciencehub.com

and based on the cost validation details cost model will be published if results are as expected or if any errors then rework will be done on cost model and issue will be fixed and recost the part to validate the results then publish the cost model.

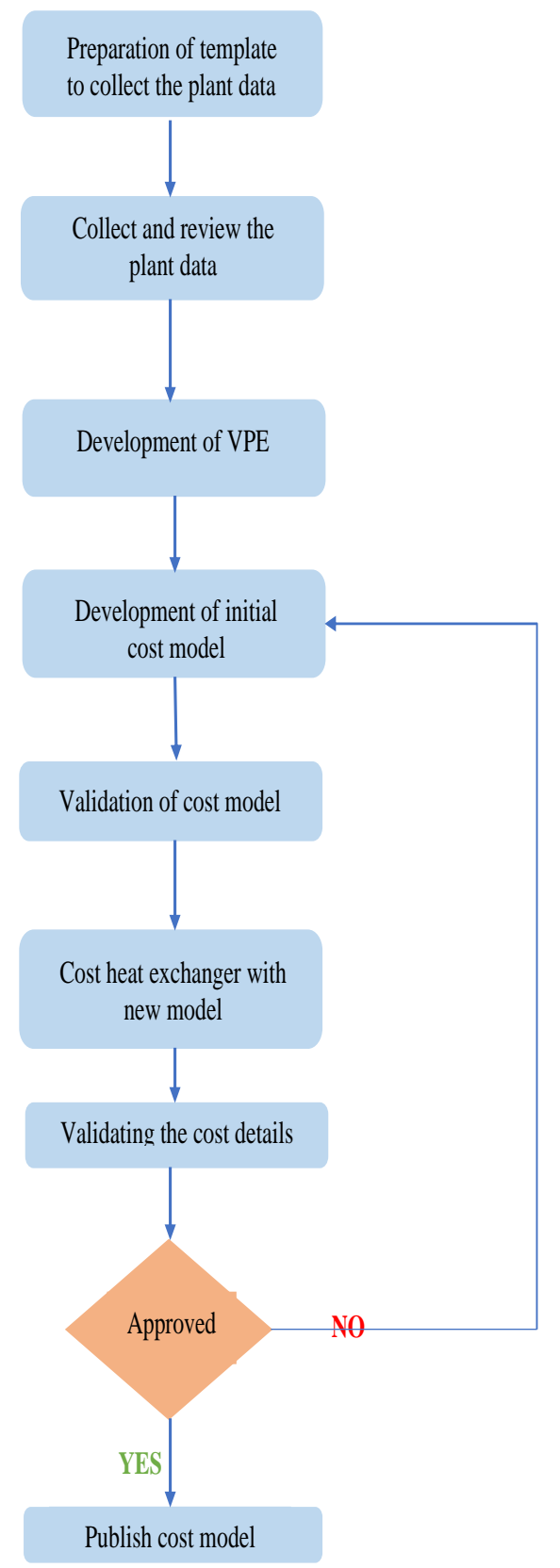

Fig. 2 Project methodology flowchart

\section{Development of Cost Model By Apriori For Heat Exchanger}

\subsection{VPE}

VPE is a digital environment where a data from a specific plant will be defined. It will act as a production environment in digital space. When a
CAD file will be imported into the aPriori environment and costing will be performed, based on plant data, which we will be defined in VPE we will come to know about more accurate cost and machine feasibility for that part. To develop the VPE required data is material data, machine data, plant data and process data.

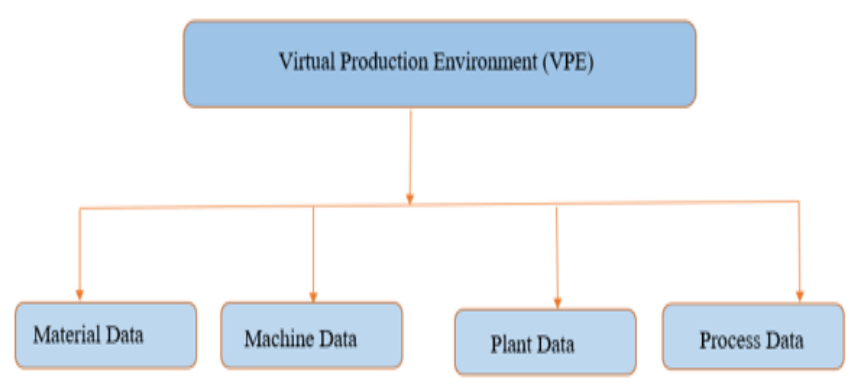

Fig 3 Elements of VPE

Fig 3 describes the elements of the VPE as material data, machine data, plant data and process data and this is the basic required data types required to develop the VPE.

\subsubsection{Material Data}

Material data contains information about materials in the plant. It is the list of different types of material available (Galvanized Steel, Copper, Aluminium), Dimension of raw material (blank size for sheet metals, including various thickness, length, and width available), the rate of material. We collect these data to define material information in VPE. Along with plant data, it contains some basic information of the material that is density of the material, Hardness, tensile yield strength, ultimate tensile strength shear strength and poisons ratio.

\subsubsection{Machine Data}

Machine data contains the list of all machines available in the plant and information about the process for which these machines are used. Machine data can be divided among two major parts, plant-specific data, and technical data. Plantspecific data contains information like name of the machine along with its make and model, the labor standard, average lot size, batch setup time, tool change time, Average utilization, good part yield, and machine life. This information is collected from the plant. In technical data, technical information related to the machine is defined as machine operation rate, machine capacity (bed 


\section{www.rspsciencehub.com}

size, maximum force, Max thickness of various materials can be operated), the gap between two parts, expandable tools information (life and price), number of operating heads of stations etc.

\subsubsection{Plant Data}

Plant Data that different plant variables required to develop the VPE is rent rate, electricity rate, gas rate, engineering support hourly rate, quality support rate, maintenance support rate, hours per shift, shifts per day, production days in year, margin percentage, SG\&A cost, fire insurance factor, loss insurance factor, engineering support allocation, Facility Water Factor etc.

\subsubsection{Process Data}

Process data contains the list of all process available in the plant and information about the operation feasibility with respect to each process in the plant. variables required for process data and process data is the different process are available in the plant as bend brake process, laser cut, laser punch, plasma cut, plasma punch, turret press, progressive die, 2 Roll Bending, tandem press, oxyfuel cut, oxyfuel punch etc.

\subsection{Cost Model (CM)}

$\mathrm{CM}$ is space where all logic and formulae are defined in this space. $\mathrm{CM}$ is written by the combination of technical languages and these languages are CSL are used to build logic and formulae. To connect VPE and CM, XML programming is used. Costing formulae, Machine, Material, Process selection rule are defined in the form of logic and formula.

\subsection{Costing formula}

Total part cost $=$ Manufacturing cost + Plant cost + Margin..........................................4 The total part cost is calculated based on three major factors as shown in equation 4 and total part cost is summation of manufacturing cost, plant cost and margin.

Manufacturing cost $=$ Material cost + Labor cost +Direct overhead cost.......................................... 5

Equation 5 describes that manufacturing cost is summation of material cost, labour cost and direct overhead rate.

Plant cost $=$ Indirect overhead cost + batch setup cost + Selling and administrative (SG\&A) cost................................................6 Equation 6 shows that Plant cost is summation of batch setup cost, SG\&A cost and indirect overhead cost.

\subsection{Logic development for cost model}

To develop the initial cost model, started to draw the flowchart according to the tasks carried out to develop the cost model. Fig 4 shows that flowchart for devolvement of initial cost model and it starts with collecting the requirements for cost model then evaluating the data does data support the cost model and required data was draw from the VPE database and if the data is sufficient then, it starts with initial cost model development activity, if not then need to update the database with required fields. After developed the initial cost model then cost model need to evaluate with respect to material, machine, routine and process validation and if the validation is success then cost assessment will be done and if the cost variables are within the targeted value then cost model will be approved and published the cost model.

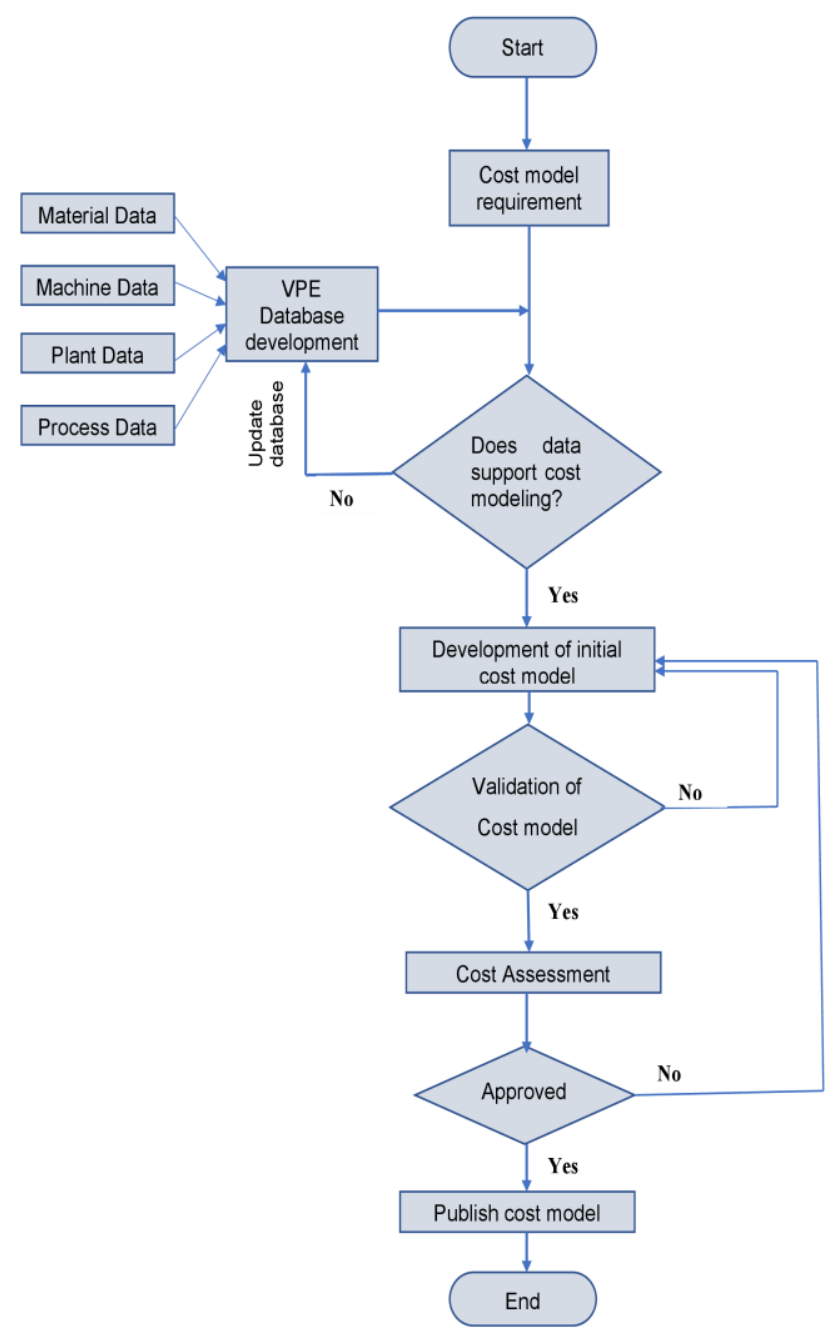

Fig 4 Flowchart for cost model development 


\subsection{Manual brazing process cost model}

Devolvement of initial cost model for manual brazing process starts with importing the CAD file into aPriori, then Geometric Cost Driver (GCD) data was extracted, then it will evaluate that gcd.total length field value is greater than zero, if yes then operation level braze length will be calculate based on gcd.total length and in process level braze length will be summation for all joints then braze cycle time calculate and if gcd.total length is less than zero then inputs are given as outside diameter, number of joints to calculate the braze cycle time. Then it will calculate the labor cost, total variable costs and full burdened cost. Then full burdened cost will be evaluate with cost assessment as cost details are within the target value then cost model will be published or rework will be done on the initial cost model and process will repeat in order to publish the cost model.

\subsection{Robotic brazing process cost model}

As need to select the robotic brazing process from process routine selection panel on user interface (UI), added the template for robotic brazing process. Robotic brazing template under component for routine selection rule and robotic brazing process will be visible on process routine selection panel on UI. Once the template was created, now need to build the process name, operations under that process and respective geometric cost drivers (GCD). After the process was defined next step is defining the CSL module, I have developed the cost taxonomy, machine selection and routine selection rule for robotic brazing process.

\subsection{Tube insertion and Tube expansion cost model}

Template was created under the component for routine selection rule in cost module work bench for tube insertion and tube expansion process. Then these process can select from process routine selection panel on user UI of aPriori. Once the template was created, now need to build the process name, operations under that process and respective geometric cost drivers (GCD) After the process was defined next step is defining the CSL module, then developed the cost taxonomy (Cost Taxonomy is the code file which contains costing formula along with Structural Query Language
(SQL) codes to connect, VPE with the cost model), machine selection ( machine selection rule makes sure that based on feature an appropriate machine should be selected. Machine selection rule is logic which says about machine capability, feasibility and low cost machine should be selected) and process routine selection rule (During the part cost estimation, it will identify the feasible process routine with low cost process) for tube expansion and tube insertion process.

\section{Result and Discussion}

VPE was developed based on the specific plant details given by the suppliers and developed the CM. In this chapter validated the defined process like manual brazing process, robotic brazing process, tube insertion and tube expansion.

\subsection{Validation of Manual Brazing Process}

When an assembly is selected in aPriori for cost estimation and created the brazing on the required joints of the assembly, then we need to do the cost the assembly with manual brazing process. In this process first, we need to select the manual brazing process from the process routine panel as shown in the Fig 5.

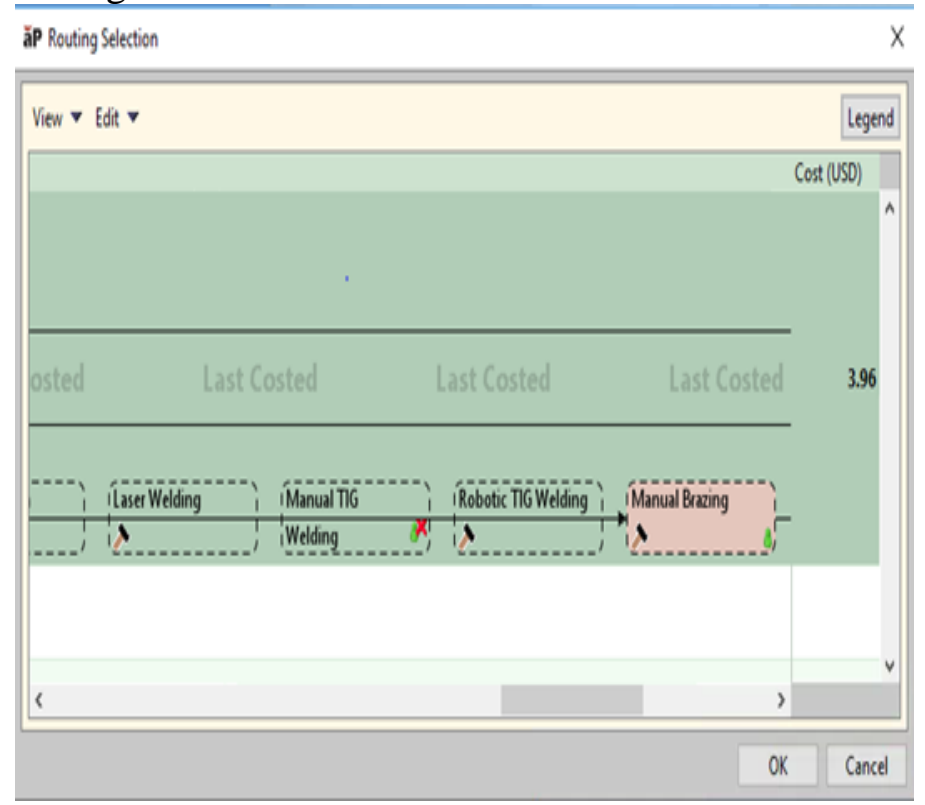

Fig 5 Screenshot of Manual brazing process is selected on routine selection

On selected assembly three brazing joints are created to validate the manufacturing times (brazing cycle time, labour time and batch setup time) and variable cost (direct cost, addition direct cost, expendable tooling cost, labor cost). Fig 6 shows that once the cost the assembly then the 
www.rspsciencehub.com

manufacture times in brazing cycle time, labor time and batch setup time shown under manufacture time section.

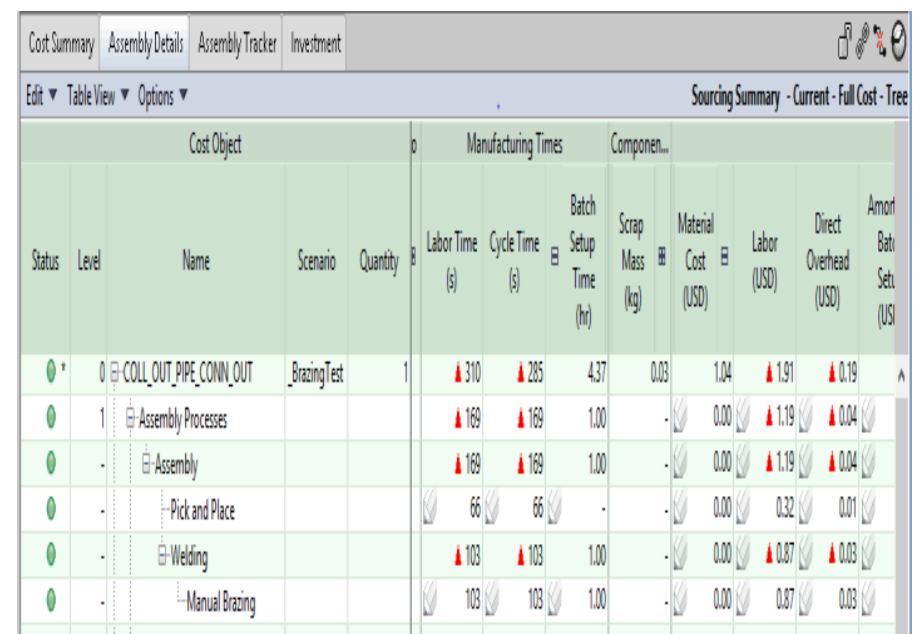

Fig 6 Screenshot of Manufacturing times for manual brazing

\subsection{Validation of Robotic Brazing Process}

When an assembly is selected in aPriori for cost estimation and created the brazing on the required joints of the assembly, then we need to do the cost the assembly with robotic brazing process. In this process first, we need to select the robotic brazing process from the process routine panel. On selected assembly having the 16 brazing joints on copper tube and return bend cap and number of braze torch, coil tube speed as process setup option will be given by the user as input. Fig 7 shows that once the cost the assembly then the manufacture times that is brazing cycle time, labor time and batch setup time shown under manufacture time section. Fig 8 shows that variable cost such as expandable tooling cost, additional direct cost and total variable cost for manual brazing process.

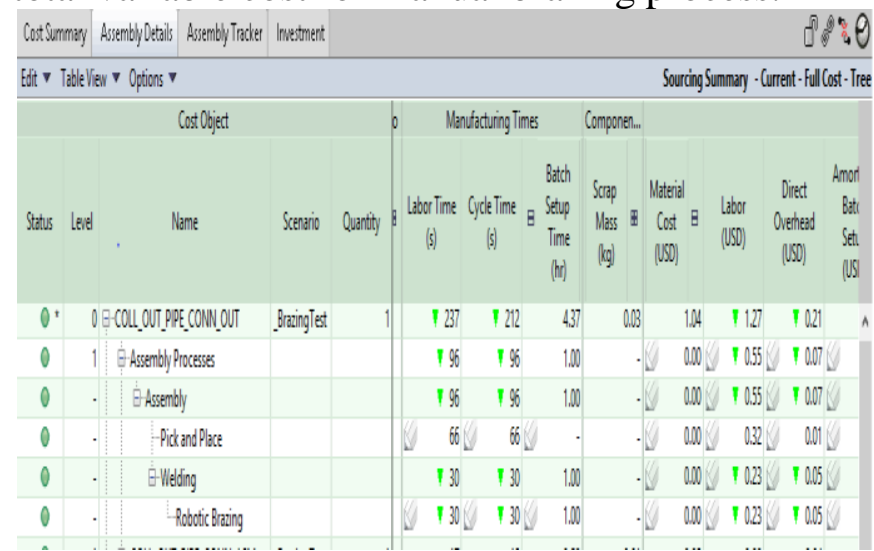

Fig 7 Screenshot of Manufacturing times for
Volume 02 Issue 10S October 2020

\section{robotic brazing}

Fig 8 shows that variable cost such as expandable tooling cost, additional direct cost and total variable cost for manual brazing process.

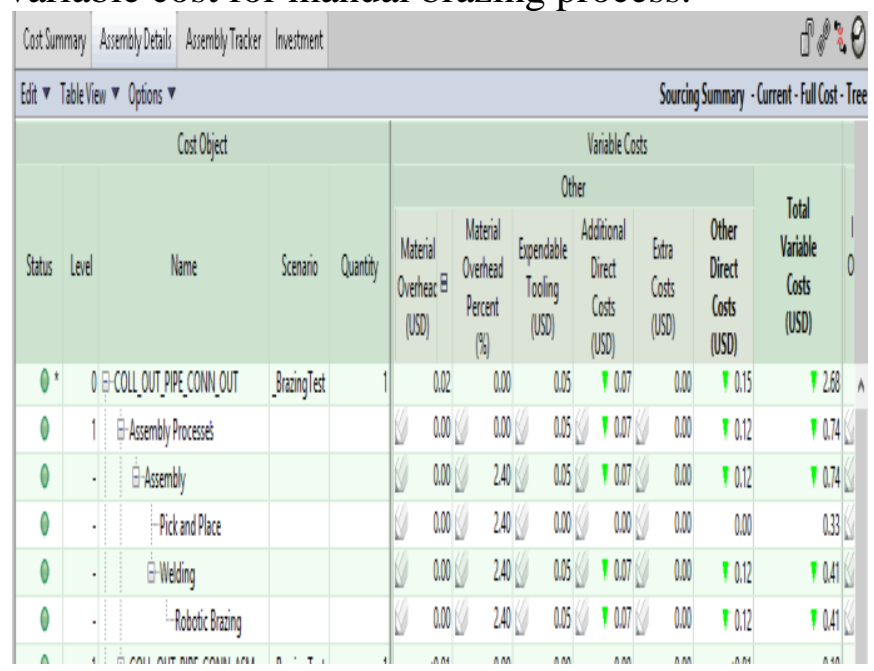

Fig 8 Screenshot of Variable costs for robotic brazing

\subsection{Validation of Tube Insertion (Lacing) Process}

When an assembly is selected in aPriori for cost estimation and then need to be select the mechanical assembly process under assembly process and user has to select the tube part then select the tube insertion process named as lacing and user has to select the lacing process from the process routine panel as shown in the Fig 9.

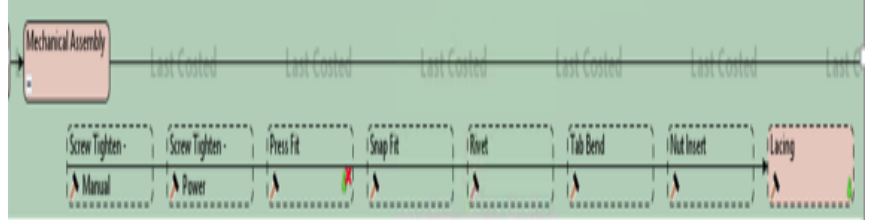

Fig 9 Screenshot of Lacing process is selected on routine selection

On selected assembly with lacing process then need to validate the manufacturing times ( cycle time, labour time and batch setup time) and process time was collected from the plant for average time required for the one tube insertion and the plant data was updated in the look up table called as mechanical assembly process look up table and based on the process type Cost script language (CSL) was coded to fetch the respective process time from the look up table and sample mechanical assembly lookup table. Fig 10 shows 


\section{www.rspsciencehub.com}

that once the cost the assembly then the manufacture times that is cycle time as 5 seconds, labor time as 5 seconds and batch setup time as 1 hours shown under manufacture time section.

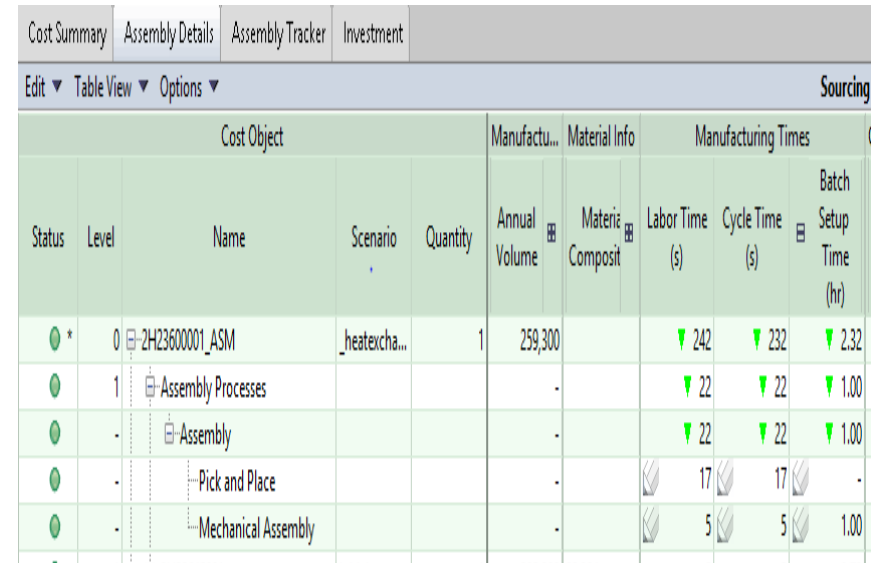

\section{Fig 10 Screenshot of Manufacturing times for} lacing process

\subsection{Heat Exchanger assembly cost and Components cost distribution}

Once the all sub components of the assembly is costed, then assembly is selected in aPriori for cost estimation and inputs will be given as process group as Assembly, VPE as Heat exchanger and volume of the part required annually and after this inputs, assembly was costed and sub components of the fin and tube heat exchanger is aluminium fins, support plate, return bend, copper tube, end cover plate, Connecting copper tube to distributor, Distributor and Fastener and these sub components are costed with aPriori cost model then assembly was costed.

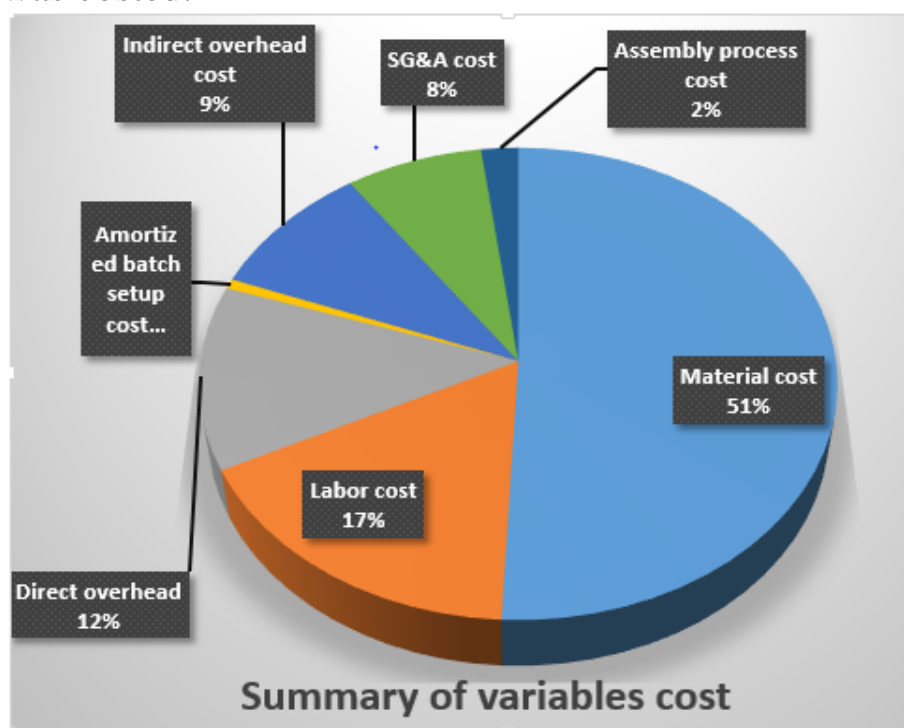

Fig 11 Heat exchanger variables cost

Fig 11 shows that heat exchanger variables cost breakup and it shows that material cost $51 \%$, labor cost $17 \%$, direct overhead $12 \%$ bath setup cost $10 \%$, indirect overhead cost $9 \%$ and SG\&A cost is $8 \%$ of total cost respectively.

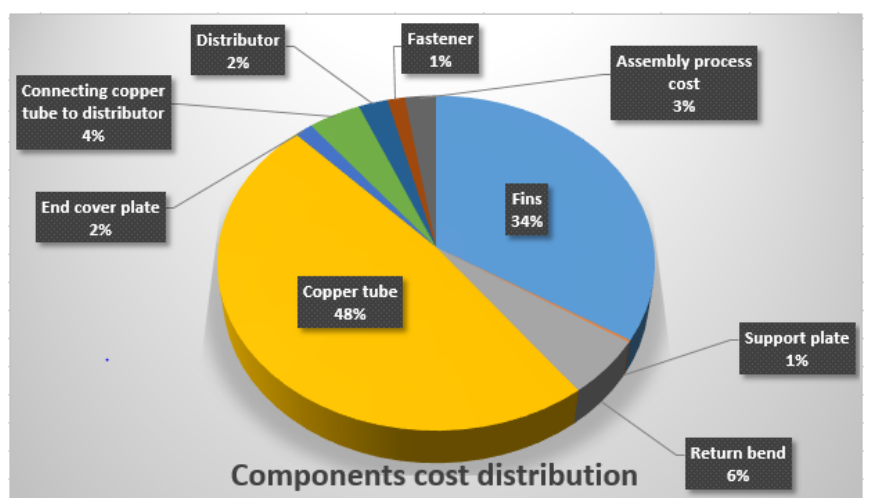

Fig 12 Components cost distribution

Fig 12 shows that heat exchanger components cost distribution and it shows that fins cost 34\%, copper tube cost $48 \%$, return bend cost $6 \%$, support plate cost $4 \%$, end cover plate cost $2 \%$, and assembly process cost $3 \%$ of total cost respectively.

\section{Conclusions}

The aim of this work was to developing an accurate, reliable and time-saving cost model for heat exchanger of Residential and Industry Applications, using the aPriori cost estimation tool. The VPE was developed based on the specific plant details given by the suppliers and developed the $\mathrm{CM}$ where did mapping of the available input and desired output and defined the cost taxonomy, machine selection rule, material selection rule and routine selection rule for all the process like sheet metal, Bar and tube, Assembly process which involves in manufacturing of heat exchanger. Validated the manufacturing times consist of cycle time 103 seconds and labor time 103 seconds and cost variables consist of labor cost $\$ 0.87$, direct overhead cost $\$ 0.03$, addition direct cost $\$ 0.20$, total variable cost $\$ 1.10$, fully burdened cost $\$$ 1.46 for manual brazing process and similarly validated the cost parameters for the robotic brazing, tube insertion, tube expansion and turret press process successfully and implemented this process in new cost model and costed the parts with this process. aPriori cost estimation model reduced the overall production time, improve the productivity and quality of the product. aPriori cost model estimated that manufacturing cost of 
www.rspsciencehub.com

fin and tube heat exchanger around annual saving $19 \%$ of manual process cost estimation of the fin and tube heat exchanger.

\section{References}

[1].Hao Zhang, MingyueWang ,Zhixuan Cheng, Ling Wan, "Technology-sharing strategy and incentive mechanism for R\&D teams of manufacturing enterprises", Journal of physica, 2020, 25, 814-828.

[2].BeniaminoAccattoli, "Efficiency and Reasonable Cost Models", Electronic notes in theoretical computer science, 2018, 338, 23-43.

[3]. TribhuvanSingha, RanvijaySingha, Krishn Kumar Mishra, "Software Cost Estimation Using Environmental Adaptation Method", Procedia Computer Science, 2018, 143, 325-332.

[4].BW Shivaraj, MV Ravishankar, "Optimization Proposal to Improve Productivity of Elongated Articles",MaterialsTodayProceedings, 2020 ,24,1595-1601.

[5]. Apoorva, V, Hemalatha, J.N, Achyutha, W.M., Shivaraj, B.W, "Steps involved while introducing a new product into a healthcare organization", Proceedings of the International Conference on Computing Methodologies and Communication, ICCMC 2017.

[6].CK Sagar, BW Shivraj, HNN Murthy, "Design, development and analysis of press tool for hook hood lock auxiliary catch", ICoRD'13, 2013, 1063-1075.

[7]. TsungYueh Lu, Shu Li Wang, Mei-Fang Wu, Feng Tsung Cheng, "Competitive Price Strategy with Activity-Based Costing-Case Study of bicycle Part company", CIRP, 2017, 63 , 14-20.

[8].Veer Shivajee, Rajesh Kr Singh, Sanjay Rastogi, "Manufacturing conversion cost reduction using quality control tools and digitalization of real time data ", journal of cleaner production, 2019, 237, 117-168.

[9]. Antonio C. Caputo, Pacifico M. Pelagagge, Paolo Salini." Manufacturing cost model for heat exchangers optimization", Applied Thermal Engineering, 2016, 94,513-533.
[10].XiaotieQina, Miao Fang, "Summarization of Software Cost Estimation", Procedia Engineering, 2011, 15, 3027-3031. 